\title{
Depression, Anxiety and Substance Use Among Undergraduate Students at North-West University, South Africa
}

\author{
Christabel M. Malebana ${ }^{1}$, Choja A. Oduaran ${ }^{1} \&$ Abimbola A. Akanni ${ }^{1,2}$, \\ ${ }^{1}$ Community Psychosocial Research Entity, North-west University, South Africa \\ ${ }^{2}$ Department of Psychology, Obafemi Awolowo University, Ile-Ife, Nigeria \\ Correspondence: Abimbola A. Akanni, Department of Psychology, Obafemi Awolowo University, Ile-Ife, Nigeria \\ ORCID id: orcid.org/0000.0002-9238-7315. E-mail: bimakanni@gmail.com
}

Received: September 28, 2019 Accepted: November 1, 2019 Online Published: November 13, 2019

doi:10.5539/gjhs.v11n13p85

URL: https://doi.org/10.5539/gjhs.v11n13p85

\begin{abstract}
Globally, there is an upsurge in the use of substance. The rate of prevalence in South Africa in recent times is worrisome, particularly among the youth population. This paper investigate the association between depression, anxiety, stress and substance use among youths at North-West University, Mafikeng campus. Data were collected from a convenient sample of 336 (female $=62.8 \%$ ) undergraduate students from the North-West university, Mafikeng campus. Results from the Pearson Product Moment Correlation analyses revealed that depression and anxiety positively correlated with substance use. That is, increased level of substance use may be linked to heightened level of depression, anxiety and substance use among undergraduates. The study revealed that depression and anxiety were responsible for the upsurge in substance use among the youth population. Thus, accessibility to existing psychosocial facilities on campus and other designated centres can provide help to students with depression and anxiety problems and consequently reduce substance use.
\end{abstract}

Keywords: anxiety, depression, substance use, youths

\section{Introduction}

Globally there is an upsurge in substance use among youths (Birhanu, Bisetegn, \& Woldeyohannes, 2014). This could be a result of the belief that substances potentially provide some relief from mental health concerns like depression and anxiety without considering the attendant public health concerns. The situation in South Africa is worrisome because substance use in form of illegal drugs doubles the world norm, with about $60 \%$ of crimes resulting from drug use (Thomson, 2013). Scholars have argued that youths indulge in substance use in order to reduce lifetime prevalence of depression and anxiety that has been put at 5\%-70\% worldwide (Sahoo \& Khess, 2010) and South Africa contributes more to these statistics. But then, substance use is a severe public health problem among youths, leading to mental challenges (Collishaw, Maughan, Natarajan, \& Pickels, 2010; Harpin, Kenyon, Kools, Bearinger, \& Ireland, 2013) that should be addressed.

The researcher's observation revealed that a substantial number of students is in danger, because of indulgence in substance as an escape route from certain mental health issues. According to Verma, Jain and Roy (2014), depression and anxiety constitute risk factors for indulging in substances use. This may sound good, but research on substance use continued to document its negative outcomes. For example, the link between substance use and poor academic performance (Mekonen, Fekadu, Mekonnen, \& Workie, 2017), violence, and suicidal ideation (Morejele, Parry, Brook, \& Kekwaletswe, 2012; Njeri \& Ngesu, 2014; Mothibi, 2014) have been reported. Furthermore, studies have established a link between anxiety and substance use (Lingford-Hughes, Potokar, \& Nutt, 2002). Others opined that no relationship existed between anxiety substance use (Brook, Cohen, \& Brook, 1998). Also, Baskin-Sommers and Foti (2015) reported a link between depression and substance use while Mossie, Kindu and Negash (2016) reported otherwise. These findings were contradictory. Therefore, the aim of this study is to ascertain the relationship between depression, anxiety and substance use.

Depression has been described as a public health problem that may lead to morbidity, disability and notable socioeconomic losses (WHO, 2012). Youths who use substances such as alcohol and tobacco have a higher level of association to depressive symptoms (Espada et al., 2011). However, youths see the use of stimulants as important drugs to reduce pain and problems. It can improve psychomotor and athletic activities (Ferrer, Marks, Midlarsky, 
\& Hutz-Midgett, 2015). This was supported by Ajayi and Ekundayo (2010) who found that youths use substances to reduce pain, and tension. Similarly, the use of alcohol (Saban \& Fisher, 2010) and cannabis (Copeland, Rooke, \& Swift, 2013) in coping with depression has been reported to be higher among adolescents and youth population.

Anxiety is an emotion that is characterized by feelings of tension and worried thoughts that often result in avoidance of feared situations (Storch \& McKay, 2013). Studies have consistently established an association between anxiety and substance use (Grant et al., 2005; Ruscio et al., 2008). Gender differences in the use of various substances in other to avoid tension and worried thoughts had been reported with male youths smoking cigarette to reduce anxiety than their female counterparts (Wu et al., 2010). This had also been reported among Kenyan students (Ndegwa, Munene, \& Oladipo, 2017). In a related manner, Yunusa, Bello, Idris and Haddad (2017) also reported among other things, that anxiety was an important factor in substance use. We therefore proposed that an association would exist between anxiety, depression and substance use among undergraduate students.

\section{Methods}

\subsection{Participants}

The study participants consisted of $336(62.8 \%)$ undergraduate students that were conveniently sampled at the North-West university (Mafikeng campus) within the age range of 18 to 25 years. The sampled participants were derived along the five major faculties at Mafikeng Campus. These are Agriculture, Education, Commerce \& Administration, Human and Social Sciences, Law and Science \& Technology. Participants' demographics is presented in Table 1.

\subsection{Instrument}

Substance use: Participants completed the Drug Abuse and Screening Test (DAST-10), a short screening tool used for the measurement of substance use in the past 12 months (Skinner \& Harvey, 2001). The short responses format consists of Yes (1) and No (0). Score 1 point for each question answered "Yes," except for item 3 for which a "No" received 1 point. DAST 10 has been reported to be appropriate for South African samples (Peltzer, Simbayi, Kalichman, Jooste, Cloete \& Mbelle, 2017). A Cronbach alpha reliability coefficient of 0.74 was reported for this study.

Depression and anxiety: This was measure by the 14 items depression (DASS-D) and anxiety (DASS-A) sections of the Depression, Anxiety and Stress scale (DASS-21), a short version developed by Lovibond and Lovibond (1995). It is a self-report 4-point Likert response format that ranged from 0 (Did not apply to me at all) to 3 (Applied to me very much, or most of the time). The scale has been used among high school students in South Africa (Masureik, Roman, Roman, \& Toefy, 2014). For this study, a Cronbach reliability coefficient of .93 was established.

\subsection{Procedure}

Two research assistants were recruited to assist in the administration of questionnaires to the university undergraduates at the North-West University, Mafikeng campus at the participants' respective faculties. Participants were required to respond to the items on the research instrument at the end of their lectures. Data collection lasted two weeks due to movement from one faculties to another as well as different classes. The completed questionnaires were retrieved for data analyses. Description of participants' demographic characteristic is presented on Table 1.

\subsection{Ethical Consideration}

The ethical approval to conduct the study was granted by the North-West University Institutional Research Ethics Regulatory Committee (NWU-IRERC). Participants were requested to sign a consent form attached to the research instrument through the independent person who also intimated them of the anonymous treatment of their responses. Furthermore, participants were made aware that their participation in the study was voluntary, and that should they feel that they were no longer interested, they were free to withdraw at any time.

\subsection{Data Analysis}

Descriptive statistics such as frequencies, percentages, mean and standard deviations were employed to describe the composition of respondents according to gender, age, academic level and race. The parametric statistics of Pearson Moment Correlation Coefficient was used to test the relationship between depression, anxiety and substance use. IBM Statistical Package for the Social Science (IBMSPSS-version 25) was adopted to analyse the data for the study. 


\section{Results}

Table 1. Descriptive statistics of respondents

\begin{tabular}{lll}
\hline Distributions & $\begin{array}{l}\text { Respondents } \\
(\mathrm{N}=336)\end{array}$ & $\begin{array}{l}\text { Percentage } \\
(\%)\end{array}$ \\
\hline Gender & 211 & $62.8 \%$ \\
Female & 125 & $37.2 \%$ \\
Male & & \\
\hline Race & 315 & $93.8 \%$ \\
Black & 17 & $5.1 \%$ \\
Coloured & 4 & $1.1 \%$ \\
White & & \\
\hline Year of study & 107 & $31.8 \%$ \\
1 st & 97 & $28.9 \%$ \\
2nd & 74 & $22.0 \%$ \\
3 rd & 58 & $17.3 \%$ \\
4th & & \\
\hline Age & 170 & $50.6 \%$ \\
$18-21$ & 49.9 & $49.4 \%$ \\
$22-25$ & &
\end{tabular}

Table 2. Mean and Standard Deviations of Depression, Anxiety and Substance use ( $\mathrm{N}=336)$

\begin{tabular}{llllllll}
\hline \multirow{2}{*}{ Levels } & \multicolumn{3}{c}{ Depression } & & \multicolumn{3}{c}{ Anxiety } \\
\cline { 2 - 3 } & $\mathrm{N}$ & $\mathrm{M}$ & $\mathrm{SD}$ & & $\mathrm{N}$ & $\mathrm{M}$ & $\mathrm{SD}$ \\
\hline Low & 220 & 1.33 & .576 & & 215 & 1.29 & .564 \\
Moderate & 75 & 1.43 & .719 & & 92 & 1.52 & .703 \\
Severe & 41 & 1.73 & .807 & & 29 & 1.86 & .833 \\
\hline
\end{tabular}

Statistical presentations in Table 2 showed that there is no significant mean difference between the independent variables and dependent variable in the study. This is evident in the means scores of most of the participants that indicated low substance use for depression $(\mathrm{X}=1.33$; $\mathrm{SD}=.576)$ and anxiety $(\mathrm{X}=1.29 ; \mathrm{SD}=.564)$ That is, many of the respondents reported that they might not even consider substance use when they are depressed or anxious. The study also revealed a moderate substance use when depressed $(\mathrm{X}=1.43 ; \mathrm{SD}=.719)$ and anxious $(\mathrm{X}=1.52 ; \mathrm{X}$ $=1.52 ; \mathrm{SD}=.703)$. This suggested that a moderate number of respondents might indulge in substance use in order to come out of depression and anxiety. 
Table 3. Correlation matrix of substance use, depression and anxiety $(n=336)$

\begin{tabular}{lllllll}
\hline Variables & $\mathbf{M}$ & SD & $\mathbf{1}$ & $\mathbf{2}$ & $\mathbf{3}$ & $\mathbf{4}$ \\
\hline 1. & 1. Age & 1.63 & .484 & 1 & & \\
\hline 2. Depression & 11.55 & 4.18 & $-.15^{* *}$ & 1 & $.732^{* *}$ & 1 \\
\hline 3. Anxiety & 11.80 & 4.40 & -.10 & $.232^{* *}$ & $.347^{* *}$ & 1 \\
\hline 4. Substance use & 12.17 & 2.09 & -.04 & & \\
\hline
\end{tabular}

Note. ${ }^{* *}$ Correlation is significantly the 0.01 level (2-tailed).

The results from Table 3 showed a significant positive relationship between depression and substance use $(r=.232$, $\mathrm{p}<.05$ ). Although a weak positive correlation existed between the variables, it suggested that when undergraduates have symptoms of depression, they are likely to consider substance use as an option. It also revealed the existence of a significant positive relationship between anxiety and substance use $(r=.347, p<.05)$. Thus, this implies that the participants have the possibility of indulging in substance use whenever they are anxious. That is, as the level of anxiety increases, substance use will also increase.

\section{Discussion}

The aim of the study was to investigate the relationship between depressions, anxiety and substance use among the youths at North-West University, Mafikeng Campus. The findings revealed a positively weak correlation between depression and substance use among youths. That is, substance use will likely increase with the level of depression among youths on Mafikeng Campus. This finding supported previous studies that established a significant positive association between depression and substance use (see Plüddemann et al., 2010; Saban \& Flisher, 2010; Oshodi, Aina, \& Onajole, 2010; Espada et al., 2011; Copeland, Rooke, \& Swift, 2013). The plausible explanation for the agreement between this finding and previous studies is that youths across the globe face closely related challenges that could possibly lead to depression. Therefore, they attempt to explore various options to come out of their depressive stage by eventually indulging in substance use. However, the weak relationship that exists could be because of the low level of substance use that was reported by the participants in the current study.

We also found anxiety to significantly and positively correlate with substance use. Previous studies have reported similar findings (Ndegwa, Munene, \& Oladipo, 2017; Yunusa, Bello, Idris, \& Haddad, 2017). These studies revealed that there is a connection between anxiety and substance use among the youth population. As evidenced in the reported findings of the empirical reviews of literature, youths indulge in substance use to treat anxiety. They believe that such substances will make the object of anxiety loose its potential threat (Storch \& McKay, 2013).

\section{Conclusion}

The study concluded that depression and anxiety might have positive relationship with the consumption of various substances among undergraduates at North-West University. Therefore, students' misconception of the capacity to handle depression and anxiety with substances like alcohol, cigarette and other drugs should be clarified and discouraged. This could be achieved by emphasizing the negative outcomes of substance use during orientation programmes. They should be encouraged to always make use of counselling and psychosocial facilities available on campus whenever they are depressed or faced with other psychological problems. However, these psychosocial facilities should be strengthened and be made attractive to encourage patronage from students experiencing anxiety or depression of any kind. It is pertinent to emphasize that clinical Psychologist should be contacted through the University's counselling unit to provide necessary psychotherapy to those who have problems with substance addition as a result of depression and anxiety.

\section{Acknowledgements}

The authors express their gratitude to the North-West University Institutional Research Ethics Regulatory Committee (NWU-IRERC) for granting the permission to conduct the study among the undergraduate students of the North-West University, Mafikeng campus.

\section{Competing Interests Statement}

There is no conflicting interest of any for on the parts of the authors.

\section{References}

Ajayi, I. A., \& Ekundayo, H. T. (2010). Contemporary issues in educational management. Lagos, Nigeria: Bolabay Publications. 
Baskin-Sommers, A. R., \& Foti, D. (2015). Abnormal reward functioning across substance use disorders and major depressive disorder: Considering reward as a diagnostic mechanism. International Journal of Psychophysiology, 98(1), 227-239. https://doi.org/10.1016/j.ijpsycho.2015.01.011

Birhanu, A. M., Bisetegn, T. A., \& Woldeyohannes, S. M. (2014). High prevalence of substance use and associated factors among high school adolescents in WoretaTown, North west Ethiopia: multi-domain factor analysis. Journal of Public Health, 14, 1186.

Brook, J. S., Cohen, P., \& Brook, D. W. (1998). Longitudinal study of co-occurring psychiatric disorders and substance abuse. Journal of American Child \& Adolescent Psychiatry, 37(3), 322-30. https://doi.org/10.1097/00004583-199803000-00018

Chandra, A., \& Batada, A. (2006). Exploring stress and coping among urban African American adolescents: The shifting lens study. Preventing chronic disease public health research, Practice, and Policy, 3, 1-10.

Collishaw, S., Maughan, B., Natarajan, L., \& Pickels, A. (2010). Trends in adolescent emotional problems in England: A comparison two national cohort twenty years apart. Journal of Child Psychology \& Psychiatry, 51, 885-894. https://doi.org/10.1111/j.1469-7610.2010.02252.x

Copeland, J., Rooke, S., \& Swift, W. (2013). Changes in cannabis use among young people: impact on mental health. Current Opinion Psychiatry, 26(4), 325-329. https://doi.org/10.1097/YCO.0b013e328361 eae5

Espada, J. P., Sussman, S., Medina, T. B. H., \& Alfonso, J. P. (2011). Relation between substance use and depression among Spanish adolescents. International Journal of Psychology and Psychological Therapy, 11(1). 79-90.

Ferrer, E., Marks, R., Midlarsky, E., \& Hutz-Midgett, A. (2015). Substance use and pain in a cohort of college students. Research Journal of Drug Abuse, 2, 1. https://doi.org/10.7243/2057-3111-2-1

Grant, B. F., Hasin, D. S., Stinson, F. S., Dawson, D. A., Ruan, W. J, Goldstein, R. B., ... Huang, B. (2005). Prevalence, correlates, co-morbidity, and comparative disability of DSM-IV generalized anxiety disorder in the USA: results from the national epidemiologic survey on alcohol and related conditions. Journal of Psychological Medicine, 35, 1747-1759. https://doi.org/10.1017/S0033291705006069

Harpins, S., Kenyon, D. B., Kools, S., Bearinger, L. H., \& Ireland, M. (2013). Correlates of emotional distress in out of home youth. Journal of Child \& Adolescent Psychiatric Nursing, 26, 110-118. https://doi.org/10.1111/jcap.12030

Lingford-Hughes, A., Potokar, J., \& Nutt, D. (2002). Treating anxiety complicated by substance misuse. Advances in Psychiatric Treatment, 8, 107-16. https://doi.org/10.1192/apt.8.2.107

Lovibond, S. H., \& Lovibond, P. F. (1995). Manual for depression anxiety stress scale (2nd ed.). Sydney: Psychology Foundation. https://doi.org/10.1037/t01004-000

Masureik, N., Roman, N. V., Roman, N. J., \& Toefy, A. (2014). Stress, anxiety levels and decision making styles of South African senior learners: Results of a science fair project. International Journal of Education, 6(3), 57-69. https://doi.org/10.5296/ije.v6i3.6128

Mekonen, T., Fekadu, W., Mekonnen, T. C., \& Workie, S. B. (2017). Substance use as a strong predictor of poor academic achievement among university students. Journal of Psychiatry, 2017, 7517450. https://doi.org/10.1155/2017/7517450

Mothibi, K. (2014). Substance use amongst high school learners in rural communities. Universal Journal of Psychology, 2(6). 181-191.

Morejele, N., Parry, C., Broo, J., \& Kekwaletswe, C. (2013). Alcohol and Drug use. American. Journal of Drug and Alcohol Studies, 13(2).

Mossie, A., Kindu, D., \& Negash, A. (2016). Depression research and treatment. https://doi.org/10.1155/2016/3460462

Ndegwa, S. Munene, A., \& Oladipo, R. (2017) Factors influencing alcohol use among university students in a Kenyan university. African Journal of Clinical Psychology, 1, 102-117.

News24.com. (2015). 15\% of South Africans have a drug problem. Retrieved from www.health24.com.

Njeri, N. A., \& Ngesu, L. (2014). Causes and effects of drug and substance abuse among secondary school students in Dagoretti division, Nairobi West District-Kenya. Global Journal of Interdisciplinary Social Sciences, 3(3), 1- 4. 
Peltzer, K., Simbayi, L., Kalichman, S., Jooste, S., Cloete, A., \& Mbelle, N. (2017). Drug use and HIV risk behaviour in three urban South African Communities. Journal of Social Sciences, 18(2), 143-149. https://doi.org/10.1080/09718923.2009.11892675

Saban, A., \& Flisher, A. J. (2010). The association between psychopathology and substance abuse in young people: A review of literature. Journal of Psychoactive Drug, 42(1), 37-47. https://doi.org/10.1080/02791072.2010.10399784

Sahoo, S., \& Khess, C. R. J. (2010). Prevalence of Depression, Anxiety, and Stress among Young Male. The Journal of Nervous and Mental Disease, 198(12). https://doi.org/10.1097/NMD.0b013e3181fe75dc

Skinner, H. A., \& Harvey, A. (2001). Assessment of substance: Drug use screening test (DAST). Encyclopedia of drugs, alcohol and addictive behaviour. Retrieved from www.encyclopedia.com.

Storch, E. A., \& McKay, D. (2013). Handbook of treating variants and complications in anxiety disorders. Journal of Medicine \& Psychology, 6, 413. https://doi.org/10.1007/978-1-4614-6458-7

Thomson, K. (2013). Overview of the drug abuse problem in South Africa. Retrieved from http://www.harmonygroup.co.za

Verma, N., Jain, M., \& Roy, P. (2014). Assessment of magnitude and grades of depression among adolescents in Raipur City, India. Journal of Medical Science, 2(5), 10-13.

World Health Organization. (2012). World suicide prevention day. Retrieved from http://www.who.int

Yunusa, U., Bello, U. L., Idris, M., Haddad, M. M., \& Adamu, D. (2017). Determinants of substance use among commercial bus drivers in Kano Metropolis, Kano State, Nigeria. American Journal of Nursing Science, 6(2), 125-130. https://doi.org/10.11648/j.ajns.20170602.16

\section{Copyrights}

Copyright for this article is retained by the author(s), with first publication rights granted to the journal.

This is an open-access article distributed under the terms and conditions of the Creative Commons Attribution license (http://creativecommons.org/licenses/by/4.0/). 